\title{
A rules based RFID-enabled supply chain process monitoring system
}

\section{Chiao-Tzu Huang*, Shu-Jen Wang, Jen-Chieh Liao and Wei-Ling Wang}

Department of Industrial Engineering and Management, National Chin-Yi University of Technology,

Chung Shan Road, Taiping District,

Taichung, Taiwan

Email: antex501@gmail.com

Email: simon@ncut.edu.tw

Email: hotrook@pchome.com.tw

Email: wlwang@ncut.edu.tw

*Corresponding author

\begin{abstract}
A supply chain management system is designated to monitor the performance and make sure that the material flow from material suppliers to customers is delivered in right time, right place and right quantity. To accelerate the information flow and accomplish real-time updated information is the major concern of the bottom-up approach. With assistance of Radio Frequency Identification (RFID), a quick response monitoring system is proposed. Even so, the visibility of the supply chain information is only supportive in development stage and not further tested explicitly in practice. Therefore, an RFID-enabled simulation will be explored and show our proposed approach in boosting the visibility of information and reducing the uncertainty existed in supply chain management. Finally, a rule-based supply chain process performance monitoring mechanism will be presented in this research; it will monitor the real-time physical flows between nodes continuously, and provide performance indicators of all levels of process.
\end{abstract}

Keywords: RFID; radio frequency identification; control chart; supply chain process.

Reference to this paper should be made as follows: Huang, C-T., Wang, S-J., Liao, J-C. and Wang, W-L. (2012) 'A rules based RFID-enabled supply chain process monitoring system', Int. J. Radio Frequency Identification Technology and Applications, Vol. 4, No. 1, pp.13-27

Biographical notes: Chiao-Tzu Huang is currently an Associate Professor at the Department of Industrial Engineering and Management, National Chin-Yi University of Technology, Taiping, Taiwan. He received his $\mathrm{PhD}$ in Industrial Department from University of Texas at Arlington, USA. His research interests are statistical process control, automation, quality management and automatic data identification system.

Shu-Jen Wang is an Associate Professor at the Department of Industrial Engineering and Management in the National Chin-Yi University of Technology, Taiping, Taiwan. He received a doctoral degree in Industrial Engineering from University of Houston. He is also certified by APICS at the level of CPIM. His research interests include supply chain simulation, logistics management, swarm intelligence and RFID applications. 
Jen-Chieh Liao is an Assistant Engineer who is specialised in RFID System Integration. He received his master degree at the Department of Industrial Management and Engineering. His research interests include supply chain simulation and RFID application.

Wei-Ling Wang is an Assistant Professor at the Department of Industrial Engineering and Management in National Chin-Yi University of Technology, Taiping, Taiwan. He teaches IE\&M courses in automatic data capture system, automatic production system and manufacture process. He was also an Instructor of EAN-Taiwan. His research areas of interest include automatic data identification system, evaluation approach and automatic production system. He has practiced automatic data capture system in many fields such as the RFID patrol system of manufacturing plant, RFID-enabled supply chain on pull-based inventory replenishment in TFT-LCD industry, RFID-enabled with data mining model for exhibition industry and two-dimensional barcode prescription-filing system for drugstore.

\section{Introduction}

In a typical supply chain system, the end-to-end workflow starts from supplier, who provides raw materials to manufacturer, whereas manufacturer provides finished product to distributor, who then distributes assorted products from several manufacturers to retailers, and finally from retailer to end consumers. As shown in Figure 1, both topdown physical product flow and bottom-up information flow simultaneously exist within any given supply chain system. Accordingly, a quick response to information changes is the essential building block for an enterprise to act on prompt response measures. According to Visich et al. (2009), they had found the implementation challenges and the corresponding strategies to enable Radio Frequency Identification (RFID) in the manufacturing environment; we believe it also has the same implementation challenges in the supply chain management environment.

Figure 1 Supply chain framework (see online version for colours)

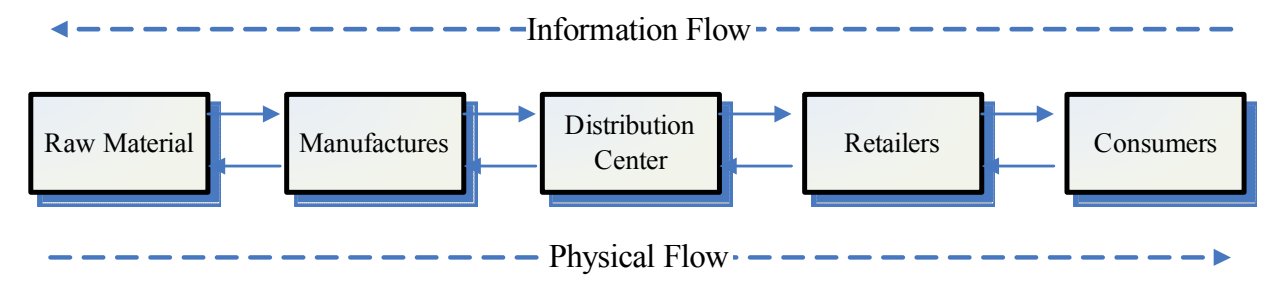

In the report of Frost \& Sullivan and Nagarajan (2005), the key findings that 510 enterprises initiating RFID tag showed that a desire for improvement of efficiency instead of enforcement is the reason for their active choice of adopting RFID. In addition to help gaining advantages in product in- and outbounding, inventory, object tracking, etc. enterprises also realise that, although not clear in practice, RFID seems to increase the visibility of supply chain. Therefore, how to enhance information visibility and logistic effectiveness becomes a major issue for the future development of RFID. 
This paper is organised as follows. Section 2 reviews the relevant literature mentioned in this study. A conceptual supply chain information system is constructed for the global TFT-LCD panel RFID-enabled supply chain of Company A in Section 3. In Section 4, a simulated case based upon an RFID-enabled TFT-LCD panel supply chain is explored to demonstrate and compare the proposed monitoring mechanism. Finally, the conclusion will be drawn in Section 5.

\section{Literature review}

In the research result of O'Connor (2005), RFID system is designed as a data storage and acquisition system that can transfer data wirelessly and provide accurate, real-time information. RFID has received a lot of attention today; Wal-Mart had mandated its suppliers to adopt RFID system. Therefore, how to enhance the visibility of information in the RFID-enabled supply chain management is vital challenge. We would like to do some investigations in this section before we start our proposed information monitoring system in this research.

\subsection{RFID system and benefits of supply chain}

Application of RFID technology has begun as early as World War II, when the sole purpose was to identify enemy aircraft. Now by inlaying a built-in wireless micro-chip, RFID is capable of recording a series of product data, such as product's category, origin of country, manufacturing date and expiration, etc. It is not until Wal-Mart and US Department of Defense announced a full-scale introduction of RFID in 2005 that it had become world-known overnight. The following is the brief description of reader and antenna - two of the most basic components comprising RFID: (a) Reader: a device to communicate between the antennas and host PC, enabling PC to capture or write information stored in the tag; (b) Antenna: a device to send radio signal (including clock, data and energy) to all tags at user-end and to receive signals transmitted back from the tags. RFID tag comes in three general varieties depending on built-in battery or not: active, passive and semi-active: (a) Active RFID tag: features with a small battery cell, rewritable data, $1 \mathrm{MB}$ memory and a transmission distance up to 100 metres. Active RFID tag is installed on product on the production line. It is capable of sending radio command to and collecting feedback from all individual equipment. Thus, all product information is stored within production history, including status such as exceeding temperature, etc. Depending on transmission distance and environment, the battery life cycle may last as long as ten years. (b) Passive RFID tag: powered by the electric field radiated from the reader instead of built-in battery, the passive RFID tag has advantages of lightweight, cheap and long life cycle, but with several shortcomings, such as shorter read distance and must work with high power reader. All read-only tags belong to this category, which usually have a 32 128 Bits ID code. (c) Semi-active RFID tag: built-in battery in semi-active RFID tag supplies energy only necessary for the operation of IC in the tag where stores all collected records. Its communication with reader has to rely on the energy provided by reader.

The EPCglobal (http://www.EPCglobal.org.tw/) is a non-profit organisation who set up global standards for RFID system. The most commonly used data representation for RFID technology initialled by EPCglobal is the Electronic Product Code (EPC), which is 
viewed by many in the industry as the next-generation of the Universal Product Code (UPC) (most often represented by a barcode). Like the UPC, the EPC consists of a series of numbers that identifies product types and the manufacturers across the supply chain. The EPC code also includes an extra set of digits to uniquely identify items.

Cooper and Yoshikawa (1994) believed the decision-making process of up- and down-stream manufacturers, data of product status during each link have a very important referential value. In today's e-commerce business world, almost all enterprises have applied or tried to adopt information system in their managing of product sales condition and other product-related information. However, current supply chain environment where no established standard workflow exists, business owners have to invest a considerable amount of manpower in collecting, inputting and compiling information, if they desire to acquire product intelligence from upstream manufacturers. A standardised information querying and exchanging mechanism, which allows integration and sharing of product information between up- and down-stream manufacturers, will enhance enterprise's competitiveness by increasing its prompt response to market and quick adjustment to product deployment.

\subsection{RFID implementation}

Delen et al. (2007) pointed out that the commodities with affixed RFID tags on pallets had reduced $16 \%$ of stock-out rate. In other words, through the RFID tags implementation, the retailer can instantly recognise the stock on store shelves, inside the storage room and automatically issue the replenishment orders. The customers can always find the right items on the shelf. Zelbst et al. (2010) build a structural model to evaluate the impacts on the supply chain performance based on the utilisation of RFID technology and supply chain information sharing. The report released by AMR Research in December 2005 showed the survey result of US retail managers, $42 \%$ of people respond that item-level tracking applications are their most important technology strategy investments by 2006-2007. To retailers' point of view, 50-60\% of people showed that investment in RFID applications in item-level stock tracking application will enhance the on-shelf availability, reduced the out-stocks rate, goods shrinkage and labour cost, the retailers selling high-priced goods also recognise such advantages.

In the findings of Market Intelligence \& Consulting Institute (MIC) (2006), US brand name apparel Ann Tayler, as well as Abercrombie \& Fitch Company, both companies adopt RFID system in the storage room and on the display shelves. The use of RFID item-level tracking will allow store personnel can quickly learn the location of each commodity and can quickly adjust the replenishment or location of commodity. According to their experience, usually have a $50 \%$ chance, merchandise is placed so that consumers cannot get on shelves. RFID item-level tracking has enabled management to obtain maximum benefits, the previous process and set-up which requires two people and two days of time to manage store inventory, and now two people only take half an hour to complete the inventory management.

\subsection{Visibility of supply chain management}

To promote supply chain management, we must first eliminate barriers among partners to let the information synchronised and share with each other partners. Liu (2007) found the success of the supply chain depends on the visibility of materials from suppliers to 
customers, if we could improve the visibility of material, then inventory management and asset utilisation will be improved. In the research result of Christopher (2000), the measurement of the visibility of the supply chain operations has significant effect on the performance of supply chain management.

Joshi (2000) developed a dynamic model to study the visibility of information in the supply chain, comparing different forecasting methods with or without information sharing; he found that in the absence of information sharing where the volatility of stock of high level and the stock of each level was also higher than the other conditions. The information sharing which enhanced the visibility of each unit of production and processing of truly meet customer needs, channel inventory significantly lower and the volatility was almost disappeared, thus reducing the overall cost of the supply chain inventory results showed that the upgrading of information visibility can reduce inventory costs from $40 \%$ to $70 \%$.

Fleisch and Tellkamp (2000) compared the traditional methods and RFID-enabled implementation, which had lifted the information sharing and improved the accuracy of inventory; even data inconsistencies still exist, but the actual stock of inventory and information systems can be immediately corrected. According to the report of the results indicates that the elimination of inventory inaccuracy can reduce inventory costs to almost zero, the adoption of automatic identification technology can effectively improve the accuracy of information. To optimise the inventory cost, Kok and Shang (2007) develop an Inspection Adjusted Base-Stock (IABS) policy for inventory replenishment in the single-period problem. They indicate that the IABS heuristic can achieve a significant value of accurate inventory information provided by RFID systems. The potential effectiveness of RFID in decreasing the inventory and enhancing the service level with simulation methods based on real data is proved by Lee et al. (2004) of the IBM, and the model is a three-tier supply chain. When information of demand moves to the upstream, Luong (2007) concludes that the bullwhip effect will appear. In the supply chain, the impact of autoregressive coefficient and lead time on the bullwhip effect is studied through a first-order autoregressive model by the retailers, based on inventory policy. Sarac et al. (2010) conclude that simulations study is one major reviewed methodology. And they also conclude that potential benefits, inventory inaccuracy problems, the bullwhip effect and replenishment policies are the major research on the impact of RFID on supply chain management.

\subsection{Track and trace (T\&T) techniques}

Zingirian et al. (2005) defined two categories of Track and Trace (T\&T): local T\&T, and wide area coverage $T \& T$. Local $T \& T$ means in-house or stationary grasping or retrieving of object mobility, while wide area coverage $T \& T$ indicated grasping or retrieving mobility of object located in external geographical areas. The purpose of T\&T is to ensure accurate delivery of all products within an effective time frame. To achieve this, in addition to real-time information of the product status during delivering process, the delivery history of transporting cargo and inspection of cargo's normal status or in-transit status are all required. By exploring the 3PL application of wide area coverage $\mathrm{T} \& \mathrm{~T}$ technology, this study aims to capture real-time cargo information, to provide integration service real-time query of product status and finally, to enhance the correctness and accuracy of workflow operation through increased information transparency. 
$\mathrm{Hu}$ (2005) found that there are four types of T\&T technologies: (a) GPS, to retrieve the actual cargo location (longitude and latitude) via US Navy satellite system; (b) webbased tracking system, a tracking system designed to cater to customer's specific needs, which comprised of three parts: web-application, customer-end interface and data bank, where the tracking system may be integrated with customer's existing operation system; (c) barcode, a data identification system, consisting of optical barcode reader for data collection and other hardware and software; (d) RFID information system, which is the main focus of the study, designed to provide large amount of simultaneous information and incorporate a comprehensive query mechanism, including statistic and dynamic data. Finally, an additional RFID with EPC Network, a derived type of RFID information established on the unified EPC Network standards, providing the same function as stated in the above RFID information system.

The penetration of each individual system differs too. GPS is capable of tracking and tracing only the package unit (e.g. a counter) instead of any comprising product unit. Web-based tracking system's capability to T\&T depends on its specification of original design. As for the barcode system, it can only read the barcode on the most outer package layer, hence the smallest traceable unit varies with how its barcode is attached or adhered. Lastly, RFID with EPC Network can read the electronic tag inside the outer package, but fails to read the inner tag, thus missing internal electronic history. In addition to several constraints imposed by US Navy, GPS has less flexibility, a limited amount of information provided and low penetration, which combined together results in an inferior benefit. All other three T\&T technologies are preferable choices when compared with GPS regarding detailed cargo information, real-time status and delivery history.

Taking RFID with EPC Network as an example by analysing RFID's features and logistic behaviour, this study will utilise LabVIEW, in line with MySQL, to develop Middleware and construct RFID-based T\&T information system.

\subsection{Process control and performance}

Based on Sir Ronald Fisher's statistics theory proposed in 1910, Statistical Process Control (SPC) was originally developed to detect variation occurring during production workflow. Subsequently, Dr. W.A. Shewhart in 1920 began applying SPC on the study and control of variation in the production process and presented his findings to the SPC field. Then, on 16 May 16 1924, Dr. Shewhart, a researcher at Bell Telephone Laboratories, further invented control chart while working on frequency distribution of product quality characteristics. After continuous refining and improving, Dr. Shewhart paved a solid theoretical foundation for future development of quality control.

The purpose of SPC is to help build an output of the production process in compliance to the designed content, that is quality of conformance involving in the quality control process. To achieve the goal, SPC method is adopted to assess output of production process to determine its acceptability. Pfohl et al. (1999) found that if any abnormality detected from comparison between the statistical analysis result of regular sampling data and preset standards, immediate stop should be imposed on the ongoing production process. Next, problem analysis on the root cause of such abnormality and follow-up corrective actions should be conducted to eliminate the abnormality before resuming normal operation. In sum, SPC is a technique aiming to maintain the stability of production process by standardisation and various preventive actions. 
Abe (1994/1997) pointed out that process performance indices could be expressed in terms of service, quality, process speed and cost. This study will address the process speed to explore the performance index, lead time which impacted the supply chain performance, uncertainty of lead time which caused supply chain members to procure more inventories for avoiding out of stock; this is so called 'bullwhip effect'. Since the uncertainty of lead time caused by members of the supply chain, if the process time could be controlled or monitored, then we will be able to effectively improve the uncertainty. The process efficiency is the performance measurement of a department process, in the supply chain framework, the limited resources of this study are difficult to be evaluated and monitored for all members of the various departments and units; therefore, this study was focused on measuring process time in between the various members of the supply chain. The statistical control charts will be adopted for monitoring the supply chain processes in various areas.

\section{System analysis and design}

In this section, the RFID-enabled monitoring system of a supply chain process will be developed, and the details for the system analysis and design are given below.

\subsection{A scenario of supply chain management}

In defining supply chain operation mode, we should first identify supply chain hierarchy, partners and the position of RFID reader, followed by description of supply chain workflow. Finally, define the significance of each supply chain section. The main system goal is defined here. With the ever-increasing product number and categories, supply chain management is becoming more complex than ever. This is especially true in situation where high immediacy and accuracy are required. To achieve higher efficiency and more flexibility of supply chain, a majority of enterprises are investing various resources in the management of supply chain. The combining advantages of immediacy, accuracy, reading/writing ability and data storing function of RFID renders higher visibility and greater command of information flow in the supply chain for the management.

Targeting at three major levels in the supply chain: manufacturer, distribution centre and retailer, and by using TFT-LCD products, RFID tags are attached on cartoons during packaging, antennas were installed at the exits of manufacture location, distribution centre warehouse, retailer's back storeroom and the entrance and exit of retailer's mall. Reader A was inlayed in the location where manufacturer writes RFID tag data (see Figure 2). The designated physical flow, which is divided into six sections: a, b, c, d, e and $\mathrm{f}$, is shown in Figure 2. The actual workflow of supply chain in practice is described as follows:

Reader A: All codes written in RFID tag are regarded as part of manufacturer's process. Supply chain starts with when the reader captures data from RFID tag during execution of this stage.

Reader B: After writing data, RFID tag is attached on cartoon waiting for racking and packaging. Reader B reads data from outbound products.

Reader C: Upon arriving at logistic provider, product is unloaded from truck, and inbound data are read. 
Reader D: After inspection and counting, product is stored or delivered outbound. Personnel at logistic provider begin selecting, racking and packaging according to orders. Outbound products are read.

Reader E: Packaged products are loaded on truck for delivery. Upon arriving at retailer's warehouse, products unloaded from truck are read.

Reader F: All products are stored in the warehouse after inspection and counting. Upon requesting from mall clerk, stored products are sent out before replenishment data being read.

Reader G: On-shelf products at the mall are being read to collect sale data when customer checks at the counter.

In Figure 2, Section ' $a$ ' represents the duration time period of RFID tag at the manufacturer after encoding; Section ' $b$ ' indicates the time period spans from LCD monitor to logistic provider; Section ' $c$ ' is the time period products stored at the logistic provider; Section ' $\mathrm{d}$ ' is the interval time period from logistic provider to retailer's mall; Section ' $\mathrm{e}$ ' is the time products stay at retailer's back storeroom; and Section ' $\mathrm{f}$ ' is the time between product put on shelf and sold.

Figure 2 RFID-based supply chain model (see online version for colours)

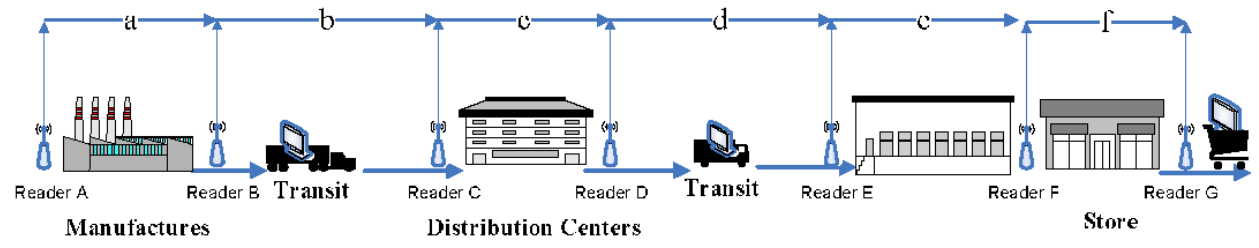

\subsection{System goal setting}

This study has developed a new mode of supply chain monitoring system. The primary goal of this system is to monitor the process performance of each partner in the supply chain and issue alarming signal of process time aberration by adopting the SPC method. Functions of the new system include: (a) inspection of supply chain workflow, the main purpose is for the users to observe the in- and outbound situation of the entire supply chain; (b) object retrieving, the main purpose is for the users to query workflow record of a specific object; (c) rules-based SPC performance monitoring, the main purpose is to monitor the performance of the entire supply chain. Except for these management functions, the new system has another additional contribution: connecting local-end Middleware with RFID reader and database server, to read RFID tag data.

\subsection{Process time monitoring}

The rule-based SPC process time monitoring method is adopted in the study featuring two types: statistic process performance query and dynamic process time monitoring. The former is to allow management review historical data and examine with control chart for the existing process performance. The latter is to generate process time by simulation, and induce it into process monitoring system, to issue real-time warning of detected abnormality. 
In the event of the performance of certain product within specific section of the supply chain being the issue of concern, the management will have to programme three parameters to define the desired monitoring range: time, product category and process interval. For example if the management wants to know how much time, the time variation and the frequency of abnormality of the 22 inch LCD during the process between inbound (from manufacturer) to outbound (from retailer) in January 2008, the system will operate to search all corresponding data within preset range, and displays abnormality on control chart after computation and analysis.

An $\bar{X}-\mathrm{S}$ chart is then adopted according to the aforesaid situational needs based on the following steps:

1 To determined control item: with process time as the time between two nodes.

2 To select sample: sampling size is $n=5$.

3 To compute the mean value $\overline{\mathrm{X}}$ and standard deviation $\mathrm{S}$, and to calculate the grand average $\overline{\bar{X}}$ and mean standard deviation $\overline{\mathrm{S}}$ of each subgroup:

$$
\begin{gathered}
\overline{\overline{\mathrm{X}}}=\frac{\sum_{i=1}^{n} \overline{\mathrm{X}} i}{m}(\overline{\mathrm{X}} \text { : sample average, } m: \text { sample subgroups }) \\
\overline{\mathrm{S}}=\frac{\sum_{i=1}^{n} \mathrm{~S}_{i}}{m}\left(\mathrm{~S}_{i}: \text { standard deviation for subgroup } i\right)
\end{gathered}
$$

4 To calculate control limit: control upper and lower limits for mean values are:

$$
\begin{aligned}
& \mathrm{CL}_{\overline{\mathrm{X}}}=\overline{\overline{\mathrm{X}}} \\
& \mathrm{UCL}_{\overline{\mathrm{X}}}=\overline{\overline{\mathrm{X}}}+A_{3} \overline{\mathrm{S}} \\
& \mathrm{LCL}_{\overline{\mathrm{X}}}=\overline{\overline{\mathrm{X}}}-A_{3} \overline{\mathrm{S}}
\end{aligned}
$$

And the control limits of standard deviation are:

$$
\begin{aligned}
& \mathrm{CL}_{\sigma}=\overline{\mathrm{S}} \\
& \mathrm{UCL}_{\sigma}=\mathrm{B}_{4} \overline{\mathrm{S}} \\
& \mathrm{LCL}_{\sigma}=\mathrm{B}_{3} \overline{\mathrm{S}}
\end{aligned}
$$

The parameters $A_{3}, B_{4}$ and $B_{3}$ could be found in any quality management textbook for building variables control chart.

As soon as all points have been plotted on the control chart, then all the exceptional points or unnatural points will be sensitising based upon the Western Electric Rules. Nelson (1984) added additional sensitising rules 'd' that the Western Electric rules are decision rules for detecting 'out-of-control' or non-random conditions on control charts. Locations of the observations relative to the control chart control limits typically at $\pm 3 \sigma$ and centre line indicate whether the process is out of control, and should be investigated for causes. 


\subsection{System design}

The system is developed upon LabVIEW platform, which is graphic-oriented language, and the system framework is shown in Figure 3. It shows how the connection works; the bottom layer is physical logistic workflow, with RFID reader as the main hardware, each of which is equipped with two antennas, installed, respectively, at manufacturer's exit, logistic provider's warehouse, retailer's storeroom and the entrance and exit of retailer's mall. RFID reader communicates with Middleware via TCP/IP.

Figure 3 System framework (see online version for colours)

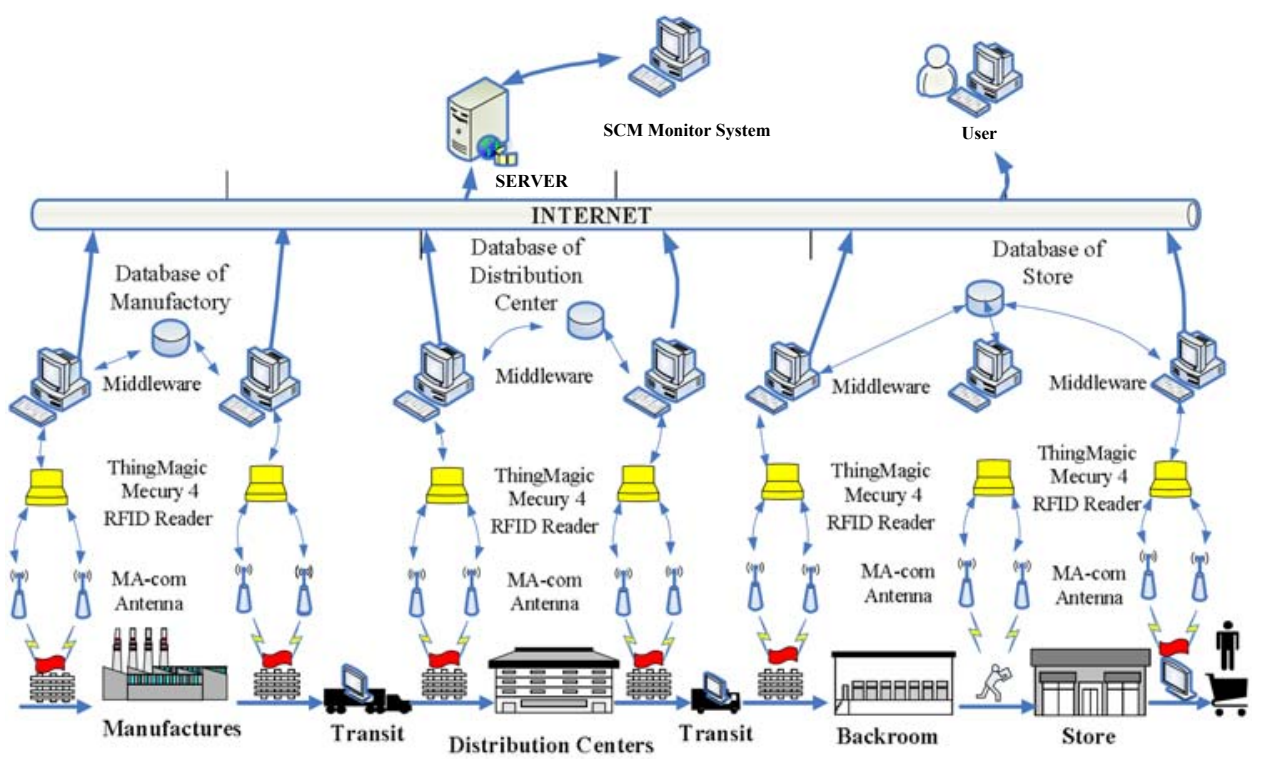

All product unique data stored in RFID tag are read by the RFID reader via Middleware upon arriving at the entrances and exits, which are then transmitted back to data bank. All incoming data are used for updating data stored in the track and trace system and process performance monitoring system.

The management may conveniently acquire from time to time the most recent and accurate logistic information via internet.

\section{Monitoring system development}

There are six major modules built up for the proposed monitoring system, and two of these modules are developed to monitor the performance of supply chain process. The first one is system Middleware and the other one is process monitoring module.

\subsection{System Middleware}

The system framework of the Middleware is shown in Figure 4. 
Figure 4 Middleware framework (see online version for colours)

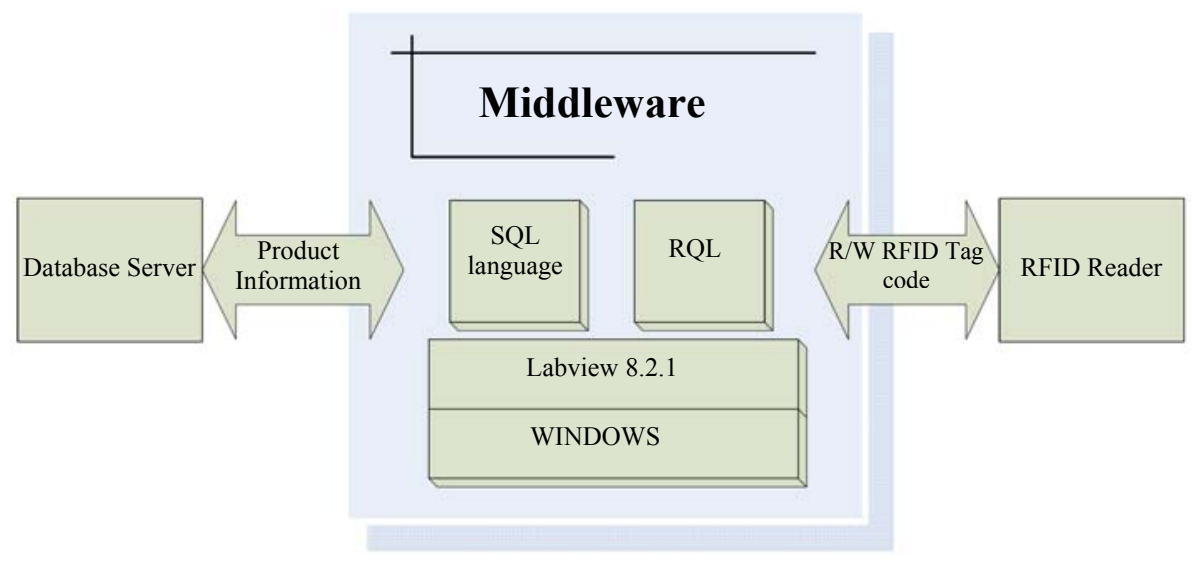

The main functions of Middleware developed for handling various inbound and outbound operation are:

- Communicating with RFID reader: To control RFID reader's activities, the local PC communicate with reader and it executes read and write RFID tag data. That is by using Middleware developed by LabVIEW, and by communicating via TCP/IP and RFID reader, to control RFID reader for the purpose of acquiring RFID tag data.

- Connecting MySQL database: By operating under Windows XP and via LabVIEW's LabSQL module, Middleware is able to connect PC with database, which allows operators to simultaneously acquire product ordering data and write in- and outbound information back to databases, theses databases of manufactures, distribution centres and stores will offer the SCM and performance monitoring system to make essential decision.

- Tag data filtering: Before sending the real-time RFID tag data back to database server, all excessive or invalid data should be filtered first, then convert the remaining valid data into a format corresponding to the system.

\subsection{Supply chain management process monitoring module}

The main functions developed for SCM process monitoring are:

- Provide in- and outbound frequency of each point in the supply chain: Once query requirements are set, user may observe the in- and outbound frequency of each point in the entire supply chain.

- Provide the in- and outbound content of each section: To detect beforehand any product batch having or will have problem and to determine the root cause of the problem through the relationship between the time and each section. Front panel developed by LabVIEW is shown in Figure 5.

- Provide product process information: Upon receiving data from the Middleware, which includes RFID code, in- and outbound time and locations, the database begins to associate RFID code with product information stored in the database, and assorts 
in- and outbound information into classification according to location and product category, and finally compiles all data into a complete unified product information history (see Figure 6).

- Provide process time performance: Process time samples plotted into the control chart, which is used to review performance, abnormal conditions and further improvement in specified time period. Based upon the Nelson's sensitivity rules, the process performance can be evaluated from the proposed charts. There are 30 samples for the 17 inch TFT-LCD panels supply chain (see Figure 7), these samples are based upon previous research result, the average duration of these data sets for manufacture to retailers which was 7.233 days and the standard deviation was 2.284 days. In the average duration chart, it showed that the average duration time exceeds the upper limit at 18th sample; even no points exceed the limits of standard deviation chart, but there are four consecutive points fall into zone 'B' which meets the Rule 6 of Nelson's sensitivity rules. Therefore, the manager should be cautioned for unnatural situation be cautioned for unnatural situation happened, further investigation need to be performed.

Figure 5 SCM monitoring module front panel (see online version for colours)

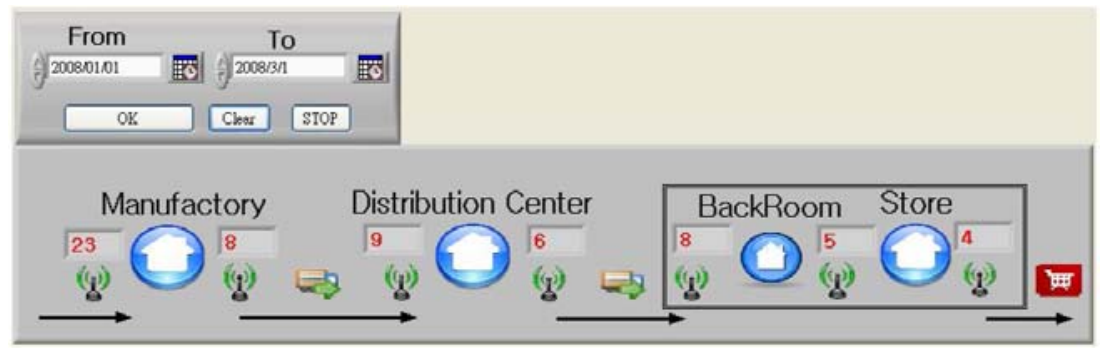

Figure 6 Manufactures' in-bound, out-bound records in designated period (see online version for colours)

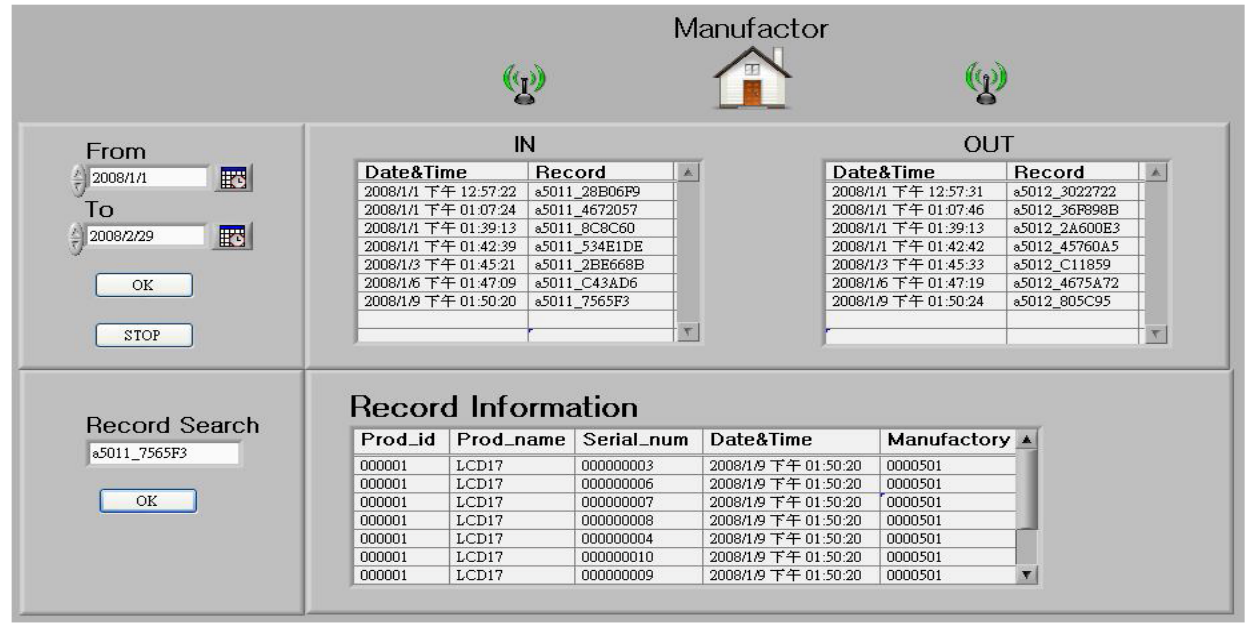


Figure 7 Process time monitoring control chart (see online version for colours)

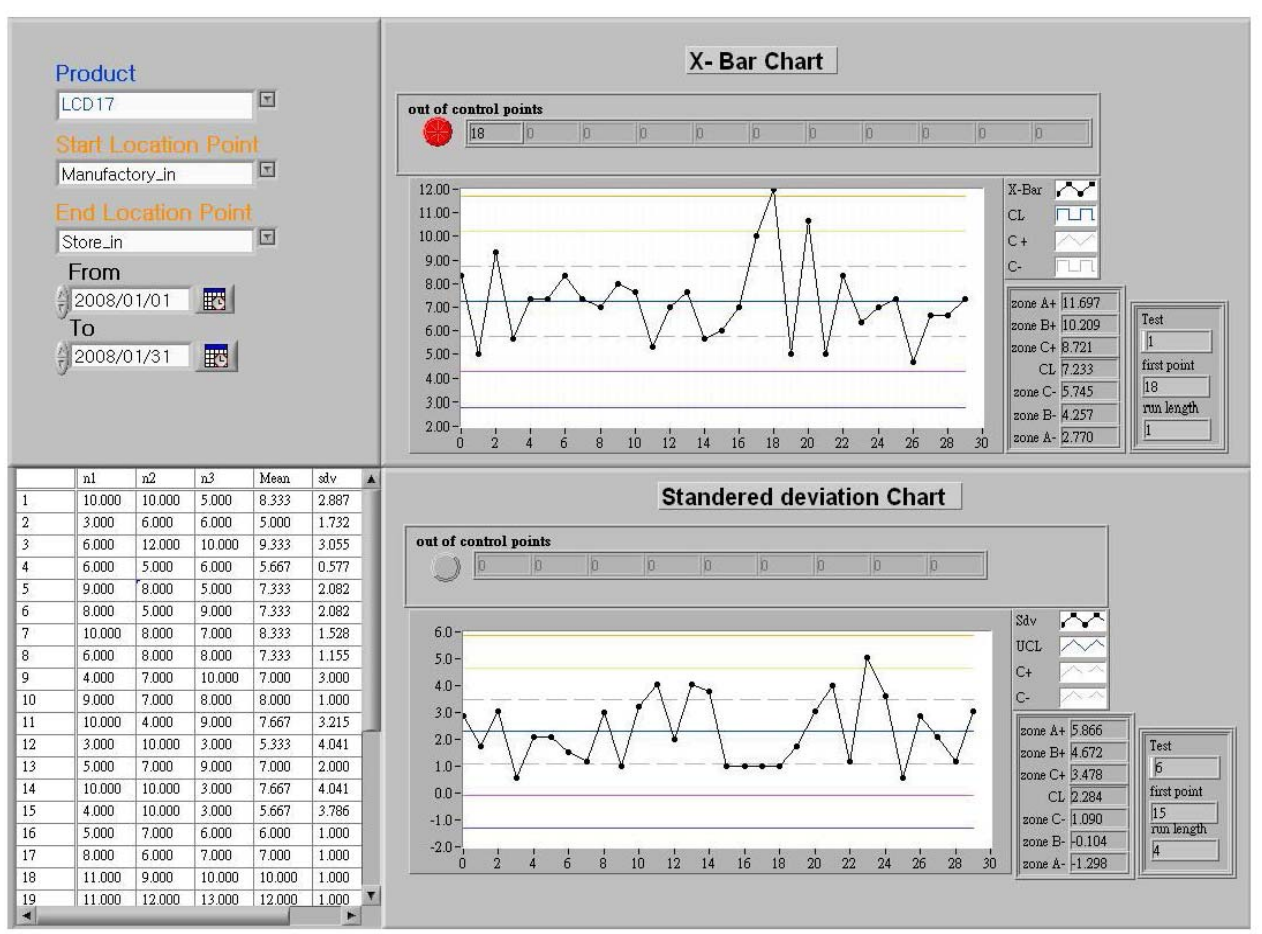

\subsection{The experiment of supply chain process monitoring module}

The experiment will focus on the simulation of the global TFT-LCD supply chain operation embedded with RFID systems in Company A. Because of the huge transactions for transmitting tagged EPC products data by real-time RFID systems, it is impossible to establish a real RFID-enabled supply chain for study. Therefore, the RFID-enabled supply chain infrastructure is mimicked and simulated based on the conceptual network structure shown in Figure 3 system framework.

To simulate and verify the system developed in this research, one-year supply chain process data sets which are described in system framework had been collected from Company A. Statistical simulation software is adopted to explore the process data and it shows that the process follow the normal distribution, then a simulated 17 inch TFT-LCD panel production events which fit the historical data are generated, the process monitoring modules front panel developed in this research is shown in Figure 8, the monitoring module can record and calculate the sampling process time for each process defined in the framework. The X-bar chart is designated for monitoring the mean value of process lead time, and the $\mathrm{S}$ chart is designated for monitoring the variation value of process.

The control limits shown in Figure 8 can be set with the historical process mean value and variation which we called benchmark values, as soon as the process or lead time exceeds the control limits or conform to the defined Nelson's sensitivity rules, the monitoring mechanism will show the warning sign on the front panel and remind the management system to make proper decision accordingly. 
Figure 8 Process monitoring module front panel (see online version for colours)

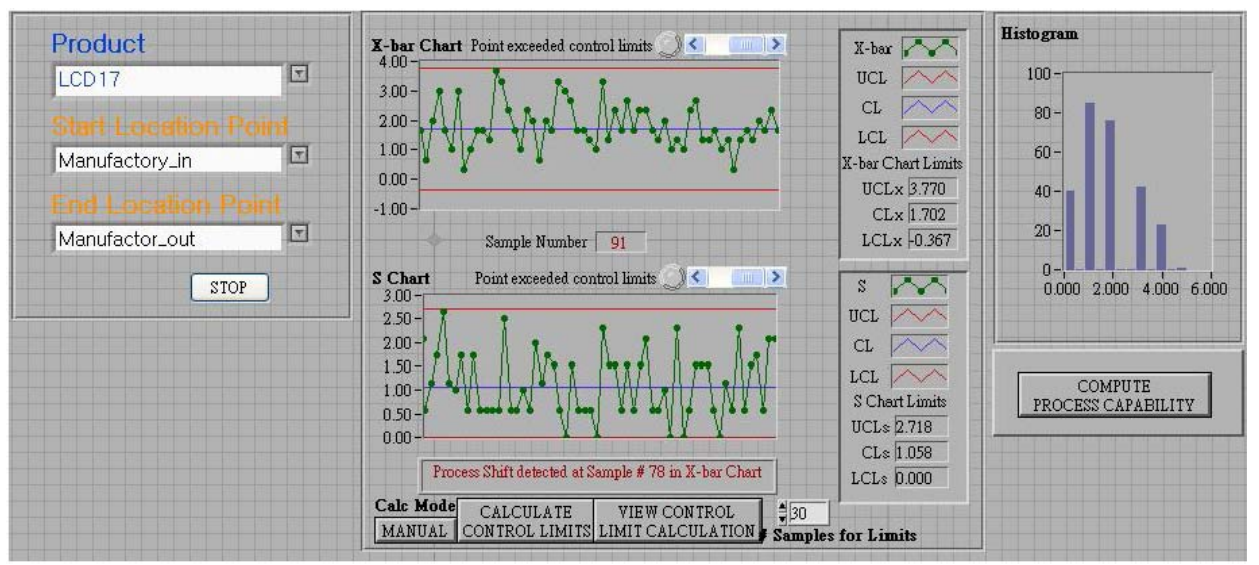

\section{Conclusion}

This research has developed a logistics track and trace system which is based upon EPC Network architecture. The system features include product major information queries, the inbound/outbound information for each section of supply chain process. This research also developed a prototype of RFID Middleware which is based upon EPC Global specification; the information of RFID tags could be retrieved, classified and coupled with additional information for users to execute performance monitoring.

With the help of track and trace technology which is developed in this research, a rule-based statistical process control technique is implemented into the supply chain process control modules, the management information system can provide more information about shipments, commodity flow and the process time performance. The managers can monitor the supply chain processes more efficiently and recognise the performance of supply chain process.

Based upon the historical information, we can construct control charts for supply chain process real-time monitoring mechanism; the manager can instantly find out whether there is an exception in the supply chain process, and monitor the process performance.

\section{References}

Abe, T. (Ed.) (1997) Business Re-engineering: A New Profitable Business Transformation (G.F. Ray, Trans.), Linking Publishing, Taipei, Taiwan.

Christopher, M. (2000) 'The agile supply chain competing in volatile markets', Industrial Marketing Management, Vol. 29, pp.37-44.

Cooper, R. and Yoshikawa, T. (1994) 'Inter-organization cost management systems: the case of the Tokyo-Yokohama-Kamakura supply chain', Journal of Production Economics, Vol. 37, No. 1, pp.51-62.

Delen, D., Hardgrave, B.C. and Sharda, R. (2007) RFID for Better Supply-Chain Management through Enhanced Information Visibility, RFID Research Center, Sam M. Walton College of Business, University of Arkansas, Information Technology Research Institute Working Paper Series. 
Fleisch, E. and Tellkamp, C. (2000) 'Inventory inaccuracy and supply chain performance: a simulation study of a retail supply chain', International Journal of Production Economics, Vol. 95, pp.373-385.

Frost \& Sullivan Report and Nagarajan, K. (2005) Analysis of RFID adoption and workforce issues in North America, Computing Technology Industry Association.

Hu, K.Y. (2005) An EPC Network based Track and Trace Information System for Logistics, Master Dissertation, National Tsing Hua University, Hsinchu City.

Joshi, Y. (2000) Information Visibility and its Effect on Supply Chain Dynamics, Master Thesis, Massachusetts Institute of Technology, MA, USA.

Kok, A.G. and Shang, K.H. (2007) 'Inspection and replenishment policies for systems with inventory record inaccuracy', Manufacturing \& Service Operations Management, Vol. 9, No. 2, pp.185-205.

Lee, Y.M., Cheng, F. and Leung, Y.T. (2004) 'Exploring the impact of RFID on supply chain dynamics', Proceedings of the 2004 Winter Simulation Conference, 5-8 December, IEEE, Piscataway, NJ, USA, pp.1145-1152.

Liu, E.C. (2007) A Research about Maximum Reading Rate for Stacking Cuboid Cartons with RFID Tag, Institute of Industrial Engineering and Management National Chin-Yi Institute of Technology.

Luong, H.T. (2007) 'Measure of bullwhip effect in supply chain with autoregressive demand process', European Journal of Operational Research, Vol. 180, No. 3, pp.1086-1097.

Nelson, L.S. (1984) 'The Shewhart control chart-test for special causes', Journal of Quality Technology, Vol. 16, pp.237-239.

O'Connor, M.C. (2005) 'Suppliers meet mandate frugally', RFID Journal, 3 January. Available online at: http://www.rfidjournal.com/article/articleview/1308/1/1/ (accessed on 22 March 2005).

Pfohl, H.C., Cullmann, O. and Stolzle, W. (1999) 'Inventory management with statistical process control: simulation and evaluation', Journal of Business Logistics, Vol. 20, No. 1, pp.101-121.

Sarac, A., Absi, N. and Dauzre-Prs, S. (2010) 'A literature review on the impact of RFID technologies on supply chain management', International Journal of Production Economics, Vol. 128, No. 1, pp.77-95.

Market Intelligence \& Consulting Institute (MIC) (2006) Taiwan Industrial Outlook, 2006: Business opportunity of Taiwan IT services industry under the worldwide RFID growing trend, Taipei, Taiwan.

Visich, J.K., Powers, J.T. and Roethlein, C.J. (2009) 'Empirical applications of RFID in the manufacturing environment international', Journal of Radio Frequency Identification Technology and Applications, Vol. 2, Nos. 3/4, pp.115-132.

Zelbst, P.J., Green Jr., K.W., Sower, V.E. and Baker, G. (2010) 'RFID utilization and information sharing: the impact on supply chain performance', Journal of Business and Industrial Marketing, Vol. 25, No. 8, pp.582-589.

Zingirian, N., Maresca, M., Baglietto, P., Ballardin, L., Bedin, S., Nalin, S. and Safiotti, F. (2005) 'CLICK \& FIND: a third-party internet service for full tracing and tracking of freight', 18th International Conference on Systems Engineering (ICSEng '05), 16-18 August 2005, pp.469-474. 